\title{
Impact of Fault Current Limiter on VSC-HVDC DC Protection
}

DOI:

10.1049/cp.2016.0426

Link to publication record in Manchester Research Explorer

\section{Citation for published version (APA):}

Chang, B., Cwikowski, O., Pei, X., Barnes, M., Shuttleworth, R., \& Smith, A. (2016). Impact of Fault Current Limiter on VSC-HVDC DC Protection. In IET 12th International Conference on AC and DC Power Transmission https://doi.org/10.1049/cp.2016.0426

\section{Published in:}

IET 12th International Conference on AC and DC Power Transmission

\section{Citing this paper}

Please note that where the full-text provided on Manchester Research Explorer is the Author Accepted Manuscript or Proof version this may differ from the final Published version. If citing, it is advised that you check and use the publisher's definitive version.

\section{General rights}

Copyright and moral rights for the publications made accessible in the Research Explorer are retained by the authors and/or other copyright owners and it is a condition of accessing publications that users recognise and abide by the legal requirements associated with these rights.

\section{Takedown policy}

If you believe that this document breaches copyright please refer to the University of Manchester's Takedown Procedures [http://man.ac.uk/04Y6Bo] or contact uml.scholarlycommunications@manchester.ac.uk providing relevant details, so we can investigate your claim.

\section{OPEN ACCESS}




\title{
Impact of Fault Current Limiter on VSC-HVDC DC Protection
}

\author{
B. Chang, O. Cwikowski, X. Pei, M. Barnes, R. Shuttleworth, A. C. Smith \\ School of Electrical and Electronic Engineering \\ The University of Manchester, Manchester, UK \\ Bin.changlpostgrad.manchester.ac.uk
}

Keywords: Fault Current Limiter; HVDC protection; multiterminal; Superconducting; VSC-HVDC;

\begin{abstract}
Multi-terminal Voltage-Sourced Converter (VSC) High Voltage Direct Current (HVDC) transmission is expected to play a key role in future power transmission grids. Compared with AC transmission, DC transmission is more vulnerable to faults due to the lower DC side impedances and sensitive power electronics used in the converters. DC protection issues must be solved before any multi-terminal VSC-HVDC grid can be established. In terms of DC protection, apart from using a DC circuit breaker to interrupt and isolate a DC fault, a Fault Current Limiter (FCL) may be employed to limit the fault current. FCLs could potentially form an important part of any future DC protection system. This paper investigates such a FCL. The main contribution of this paper is that, the resistive type superconducting FCL (SCFCL) is modelled in detail to perform $\mathrm{DC}$ protection with the $\mathrm{ABB}$ hybrid circuit breaker, in a high fidelity four-terminal VSC-HVDC system model. The simulation results show that the SCFCL has great potential to be employed for DC protection.
\end{abstract}

\section{Introduction}

DC transmission is expected to play an important role in linking offshore windfarms to the onshore power system. In Europe, projects like Borwin1 and Helwin2, etc. are based on DC technology to transmit offshore wind power to onshore grid $[1,2]$. Projects in China include the Nan'ao and the Zhou'shan projects $[3,4]$.

There are the two types of High Voltage Direct Current (HVDC) transmission technologies: Current-Sourced Converter (CSC) and Voltage-Sourced Converter (VSC), VSC-HVDC offers advantages over CSC-HVDC for power transmission, such as that it can support weak AC systems, its compactness, flexible control of active and reactive power. Additionally, cheaper XLPE cable could be used in a VSCHVDC system, as power flow reversal in VSC-HVDC is realised without reversing the DC voltage. Thus VSC-HVDC is seen to be a more practical solution for transmitting offshore electrical energy to land. In addition, a multiterminal DC grid can be established by using VSC-HVDC. Such a grid can potentially improve the reliability of the DC system; it can better handle the intermittent issues caused by the wind energy than a point-to-point system, and a multiterminal system can maximise the use of converters [5].
The study of HVDC grid capable protection systems is essential in order to enable the development of a multiterminal VSC-HVDC grid. Using HVDC circuit breakers to interrupt and isolate a DC fault has been discussed in literature, such as in [6-10] and industrial DC circuit breaker prototypes are being produced [7, 11, 12]. A Fault Current Limiter (FCL) may be used to limit the fault current the DC circuit breaker needs to interrupt. FCLs and DC circuit breakers may be required to work together to provide shortcircuit protection.

Initially, FCLs were developed to deal with AC system fault currents. Based on [13], the requirements for FCLs are:

- It should have low impedance during normal operation this will reduce the losses during normal system operation.

- It should limit the fault current within a short period of time.

- It should take a short time to recover after the fault has been cleared.

- The FCL should be designed in a way that the fault current is still limited even if the FCL fails.

- For an offshore application, the FCL should have compact structure and light weight.

- It should be able to be easily scaled up for high voltage applications.

In [14-16], a good analysis has been performed by using the superconducting FCL (SCFCL) to mitigate fault current but their simulations provide limited detail beyond current magnitude reduction. In this paper, the two-level converter is modelled with detailed switching model, the MMC is modelled with detailed equivalent model, the DC cable models are frequency dependent phase models, the DC circuit breakers are the hybrid switching models and the SCFCLs used in this paper are modelled in great detail. Using such a high fidelity VSC system models, along with a proper DC fault detection and location algorithm, this paper studies the impact the SCFCL exerts on the DC protection system and the DC circuit breakers during a DC side fault.

\section{System description and modelling}

The example system used in this paper is a four-terminal VSCHVDC system, shown in Figure 1. This system uses both twolevel and modular multilevel converter (MMC) topologies. In this system, converter stations A, B and D connect three stiff AC networks, a fourth terminal connects the aggregated windfarm to the system. In steady state, the offshore windfarm is sending $200 \mathrm{MW}$ power to the HVDC system. Converter station A will send $1000 \mathrm{MW}$ to the HVDC system. Converter 


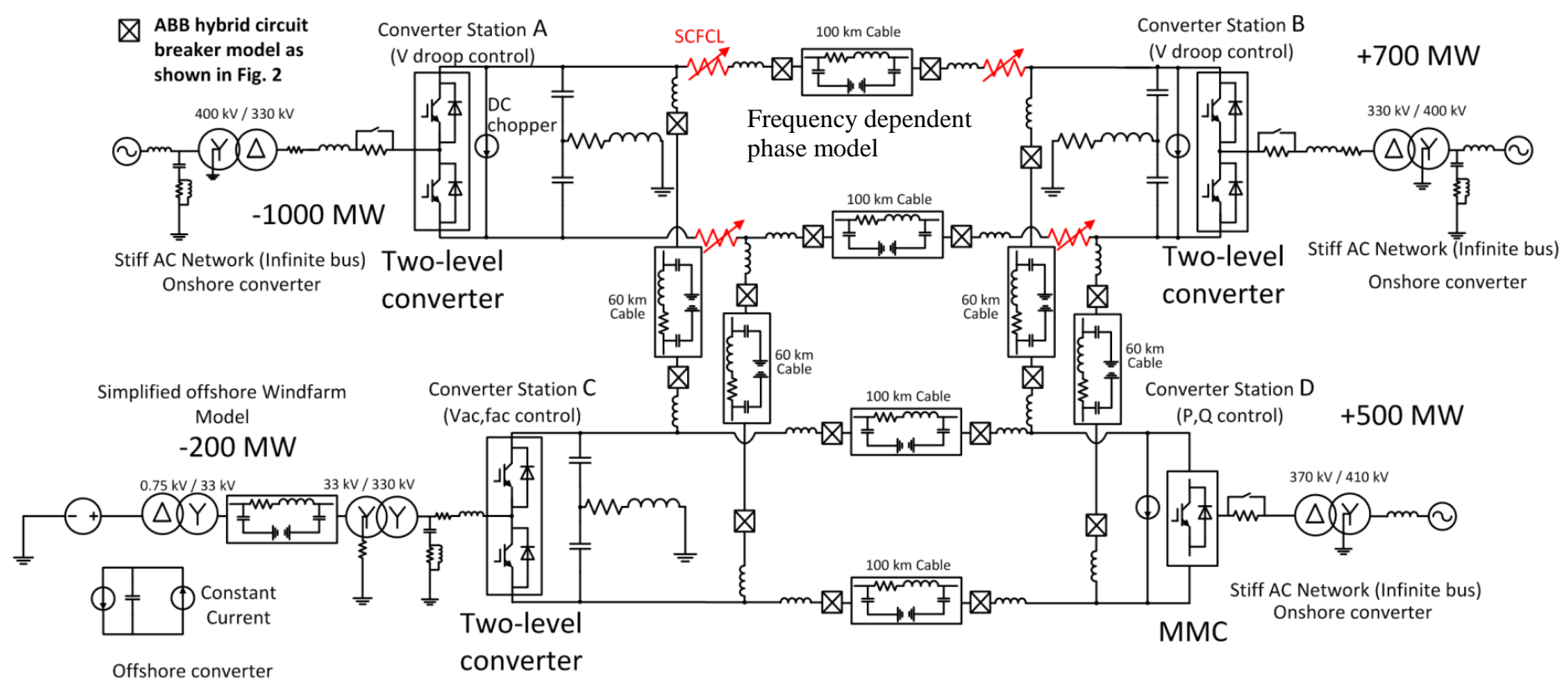

Figure 1: Schematic diagram of the multi-terminal VSC-HVDC system.

stations B and D will receive $700 \mathrm{MW}$ and $500 \mathrm{MW}$ respectively.

\subsection{Hybrid DC circuit breaker modelling}

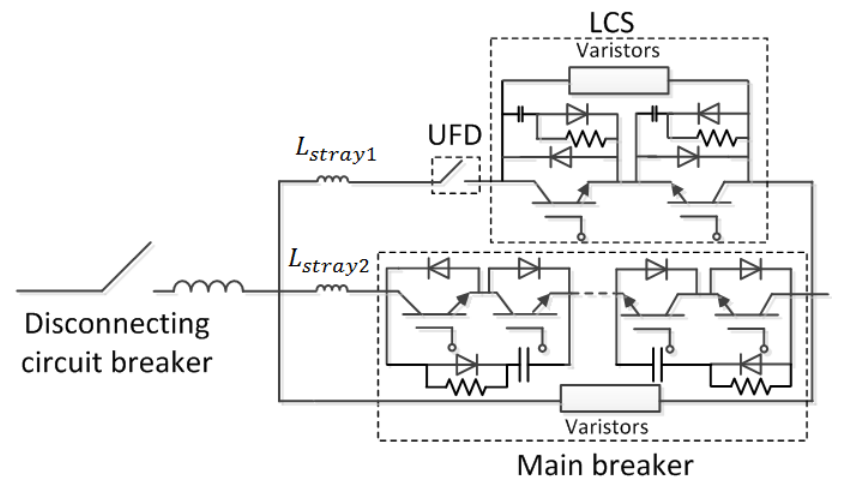

Figure 2: Schematic diagram of ABB hybrid circuit breaker model

Figure 2 illustrates the schematic diagram of the hybrid circuit breaker of the type designed by ABB. LCS is the Load Commutation Switch; UFD is the Ultra-Fast Disconnector. The detailed operation algorithm of this hybrid circuit breaker can be found in [7]. Upon receiving the signal to open the breaker, the LCS will turn off to commutate load current from the LCS into the main breaker. Once the current is fully commutated to the main breaker, the UFD will open. When the UFD reaches the fully open position, the main breaker will then interrupt the load current. After the main breaker turns off, the DC side fault is isolated. At this stage, the disconnecting circuit breaker will open.

\subsection{Onshore two-level converter modelling}

The onshore two-level converters are modelled with switched IGBTs, phase reactors, transformers, HVDC cable and DC link capacitors. For the converter control, several control methods have been proposed for the multi-terminal DC system, like voltage margin control, voltage droop control, etc. [17] [18]. In terms of the onshore converter control, this paper employs the voltage droop control and the control structure is

from [19].

\subsection{Offshore two-level converter modelling}

In terms of the offshore converter control, [20] suggests that the windfarm side VSC converter is normally configured to support the offshore AC grid voltage and frequency. This control configuration is used in this paper. Additionally, based on [21], a second order filter has been implemented and placed at the AC side of the offshore converter. This filter is employed to filter out the converter switching harmonics.

\subsection{DC chopper modelling}

DC choppers have been connected at each onshore converter's DC terminals to regulate the DC link voltage; the DC chopper is implemented based on [22].

\subsection{MMC modelling}

In terms of the MMC modelling, different types of MMC model have been proposed in [23-25]. Notably are the Accelerated Model (AM), Detailed Equivalent Model (DEM) and Traditional Detailed Model (TDM). In this paper, the DEM is used for the MMC modelling, as the DEM can provide identical system response when compared to the TDM, but takes less time to run and the DEM can give more accurate simulation results than the AM [25]. In this paper, in the implemented MMC model, there are 30 sub-modules in each phase arm which could provide 31 voltage levels. The MMC station is set to control the active and reactive power flow. Figure 3 shows the control structure for such a MMC system, modified from [26].

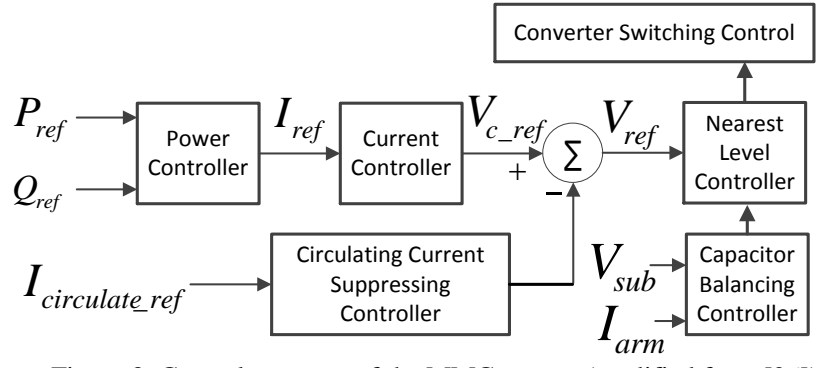

Figure 3: Control structure of the MMC system (modified from [26]) 


\section{Fault Current Limiter Modelling}

This paper will discuss the modelling of the resistive type superconducting FCL (SCFCL).

For certain materials, such as YBCO and BSCCO, when the temperature in these materials drops below a critical temperature and the current density of these materials is lower than the critical current density and the magnetic field across the materials is lower than the critical magnetic field, these materials will exhibit zero resistivity to DC [27]. With a properly designed cooling system for these materials, they can be used as elements in power system which can limit fault current. During normal operation, the load current is lower than the critical current and the temperature of these materials stays below the critical temperature, which means the normal operation losses of the conductor are approximately zero. When a short-circuit fault occurs, the fault current starts to increase. Once the fault current is greater than the critical current, the SCFCL starts to develop some resistance. Due to the presence of this resistance, the conductor is heated rapidly and the temperature of the conductor will rise above the critical temperature. After that, the resistance of the conductor increases further and the fault current will be further limited.

There are three methods to model the SCFCL.

\subsection{Two-state Resistor Modelling Method (Method 1)}

This type of SCFCL modelling is proposed in [28]. During normal operation, the resistance of the SCFCL, $R_{S C}$, is approximately zero. After the fault occurs, $R_{S C}$ is instantly increased to a fixed non-zero value to limit the fault current. The SCFCL is effectively modelled by a two-state resistor. For this SCFCL modelling method, the system transient current response is inaccurate, since the model does not consider the dynamic response of the SCFCL during the fault transient period.

\section{2 "Exponential" SCFCL Modelling Method (Method 2)}

To overcome the drawback of the two-state resistor modelling, the "exponential" SCFCL model is proposed in [29, 30]. Based on this method, when the fault occurs, $R_{S C}$ develops over time and the relationship between time, t, and resistance, $R_{S C}$, is:

$$
R_{S C}=R_{\max }\left(1-e^{-t / T_{S c}}\right)
$$

$R_{\max }$ is the maximum quench resistance. $T_{s c}$ is the time constant for the resistance of the superconductor to increase from approximately $0 \Omega$ to the maximum quench resistance.

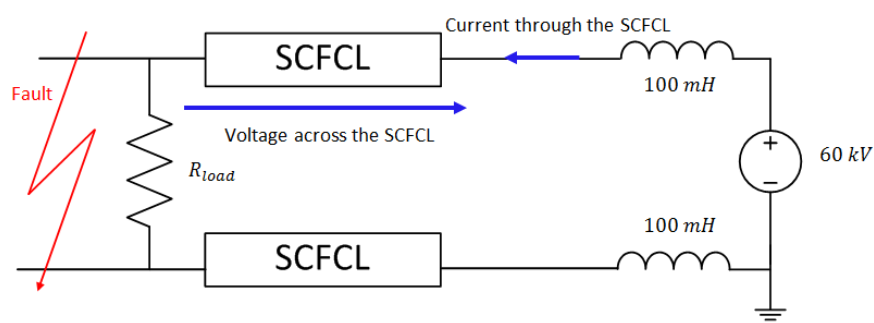

Figure 4: SCFCL Testing System

The response of the SCFCL based on this modelling method is tested in a DC system, as shown in Figure 4. In this testing system, the DC voltage is $60 \mathrm{kV}$ and the normal load current is $1.5 \mathrm{kA}$. The critical current of the SCFCL is set to be $1.8 \mathrm{kA}$ and the maximum resistance of the SCFCL is set to be $30 \Omega$. A pole-to-pole fault is introduced to this system at 0.5 seconds. Figure 5 shows the response of the SCFCL under such fault.
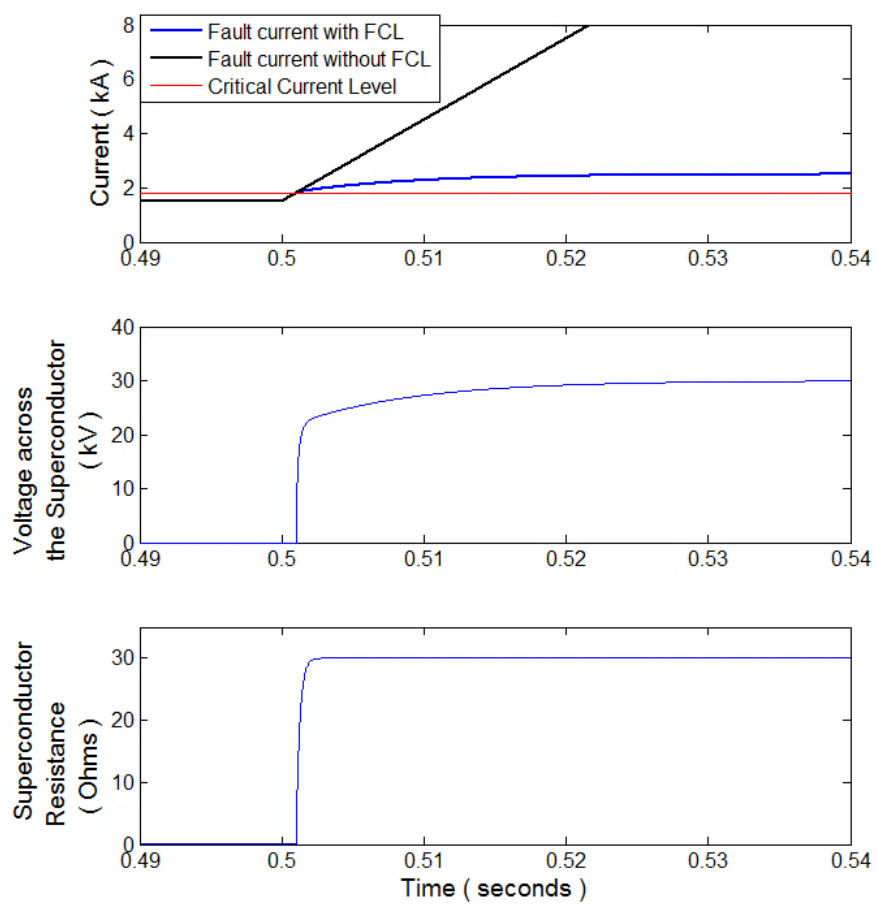

Figure 5: PSCAD simulation result of the dynamic response of the resistance of the SCFCL based on the 'exponential' SCFCL modelling method

As can be seen in the first graph of Figure 5, with the help of the SCFCL, the fault current is limited to a low value. There is a delay in the changing of the SCFCL resistance; this is because it takes a finite amount of time for the fault current to increase beyond the critical current. Once the fault current is beyond the critical current, the resistance of the SCFCL will start to increase to quench the fault current.

However, there are some drawbacks when using this modelling method for SCFCL. Based on this method, after the SCFCL quenches the fault current, the resistance of the SCFCL will increase to a fixed value; this is not accurate as physically the resistance of the SCFCL will vary during the quenching stage. In addition, this modelling method cannot provide any information about the temperature of the SCFCL. Knowing the temperature of the SCFCL during the quenching stage is important as this can help the design of the SCFCL cooling system.

\subsection{Detailed SCFCL Modelling Method (Method 3)}

Based on $[14,16,31]$, the conduction state of the superconductor can be divided into three regions: flux-creep, flux-flow and normal conducting regions. In the flux-creep region, the resistance of the SCFCL is zero. If the current density of the SCFCL exceeds $J_{0}$, which is the critical current density of the SCFCL in this case, the SCFCL will transit to the flux-flow region and the resistance of the SCFCL will rapidly increase. In the flux-flow region, the SCFCL will quickly be heated up by the current. When the temperature of the SCFCL increases above the critical temperature of the SCFCL, the SCFCL will enter the normal conducting stage 
and the resistance of the SCFCL will be determined by the temperature.

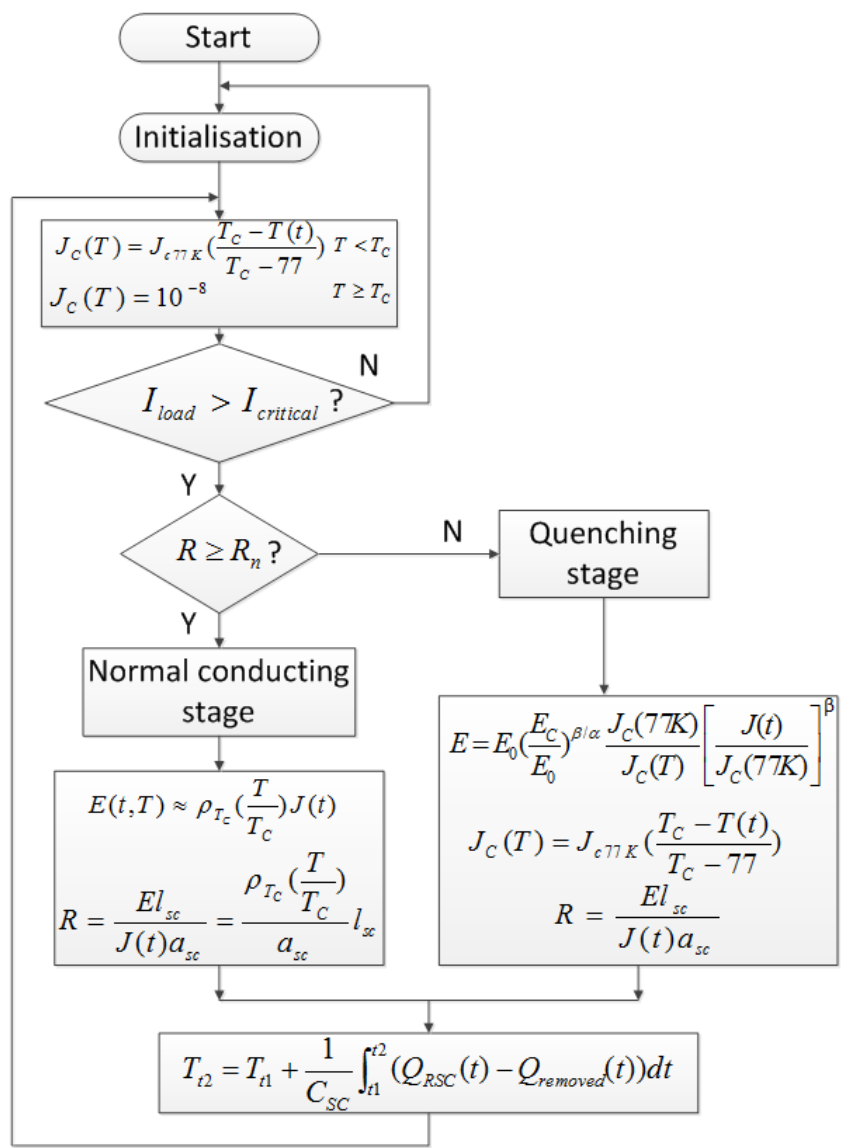

Figure 6: Algorithm of the implemented SCFCL (modified from [32])

During each conduction stage, the relationship between $\mathrm{E}$ and $\mathrm{J}$ are illustrated below. E is the electric field across the SCFCL and $\mathbf{J}$ is the current density of the SCFCL.

1) Flux-creep stage (Superconducting stage):

$$
\mathrm{E}=\mathrm{E}_{\mathrm{C}}\left(\mathrm{J} / \mathrm{J}_{\mathrm{c}}(\mathrm{T})\right)^{\alpha}
$$

2) Flux-flow stage (Quenching stage):

$$
\begin{gathered}
\mathrm{E}=\mathrm{E}_{0}\left(\mathrm{E}_{\mathrm{C}} / \mathrm{E}_{0}\right)^{\beta / \alpha(77 \mathrm{~K})} \mathrm{J}_{\mathrm{C}}(77 \mathrm{~K})\left(\mathrm{J} / \mathrm{J}_{\mathrm{c}}(77 \mathrm{~K})\right)^{\beta} / \mathrm{J}_{\mathrm{C}}(\mathrm{T}) \\
\mathrm{J}_{\mathrm{c}}(\mathrm{T}) \approx \mathrm{J}_{\mathrm{C} 7 \mathrm{~K}}\left(\mathrm{~T}_{\mathrm{c}}-\mathrm{T}(\mathrm{t})\right) /\left(\mathrm{T}_{\mathrm{c}}-77 \mathrm{~K}\right) \\
\mathrm{R}_{\mathrm{SC}}=\mathrm{El}_{\mathrm{SC}} /\left(\mathrm{J}(\mathrm{t}) \mathrm{a}_{\mathrm{SC}}\right)
\end{gathered}
$$

3) Normal conducting stage:

$$
\begin{gathered}
\mathrm{E}(\mathrm{t}, \mathrm{T}) \approx \rho_{\mathrm{T}_{\mathrm{C}}}\left(\mathrm{T} / \mathrm{T}_{\mathrm{C}}\right) \mathrm{J}(\mathrm{t}) \\
\mathrm{R}_{\mathrm{SC}}=\frac{\mathrm{E} \mathrm{l}_{\mathrm{SC}}}{\mathrm{J}(\mathrm{t}) \mathrm{a}_{\mathrm{SC}}}=\frac{\rho_{\mathrm{T}_{\mathrm{C}}\left(\mathrm{T} / \mathrm{T}_{\mathrm{C}}\right) \mathrm{J}(\mathrm{t}) \mathrm{l}_{\mathrm{SC}}}^{\mathrm{J}(\mathrm{t}) \mathrm{a}_{\mathrm{SC}}}=\rho_{\mathrm{T}_{\mathrm{C}}}\left(\mathrm{T} / \mathrm{T}_{\mathrm{C}}\right) \mathrm{l}_{\mathrm{SC}} / \mathrm{a}_{\mathrm{SC}}}{}
\end{gathered}
$$

In the simulation, it can be assumed that the resistance is zero during the superconducting stage. $\alpha$ is the flux-creep region constant and $\beta$ is the flux-flow region constant.

Please see the appendix for the values chosen to be used in the SCFCL modelling. Figure 6 illustrates the algorithm of the implemented superconductor model in PSCAD. Method 3 is used from this point on and example results are shown in Figure 9 and Figure 11.

\section{DC protection system design}

Various methods have been proposed for DC fault detection, such as overcurrent, derivative, and wavelet transforms, etc. $[33,34]$. The continuous wavelet transform (CWT) method has been chosen to conduct DC protection in this paper. The continuous wavelet transform takes the form:

$$
\begin{gathered}
\text { CWT }=\int_{-\infty}^{+\infty} f(t) \cdot \Psi_{a, b}^{*}(t) d t, \\
\text { where } \Psi_{a, b}^{*}(t)=(1 / \sqrt{a}) \Psi\left(\frac{t-b}{a}\right) .
\end{gathered}
$$

where $a$ is the scale or window size, and $\mathrm{b}$ is the position. A DC fault can be detected if the obtained wavelet coefficient is greater than the threshold value.

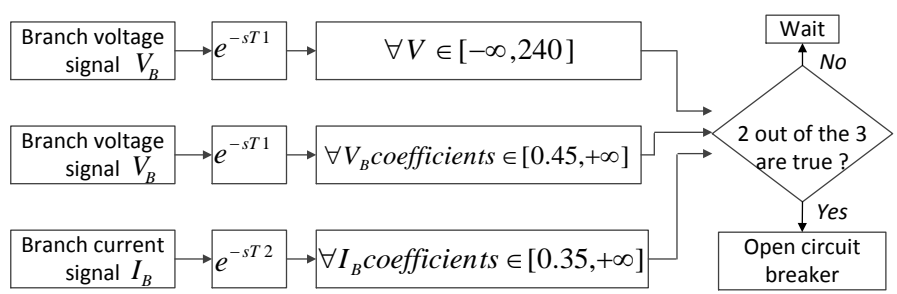

Figure 7: Protection system structure

Figure 7 shows the DC protection algorithm where 2 of 3 signals are used to detect a fault. This algorithm is modified from [33]. Figure 8 shows the location of each measured signal in Figure 7. The threshold value set to perform the DC protection is determined through sensitivity study for the system shown in Figure 1. When obtaining voltage and current signals, based on $[35,36]$, the voltage measurement delay $\left(T_{1}\right)$ is around 33 microseconds and the current measurement delay $\left(T_{2}\right)$ is around 40 microseconds.

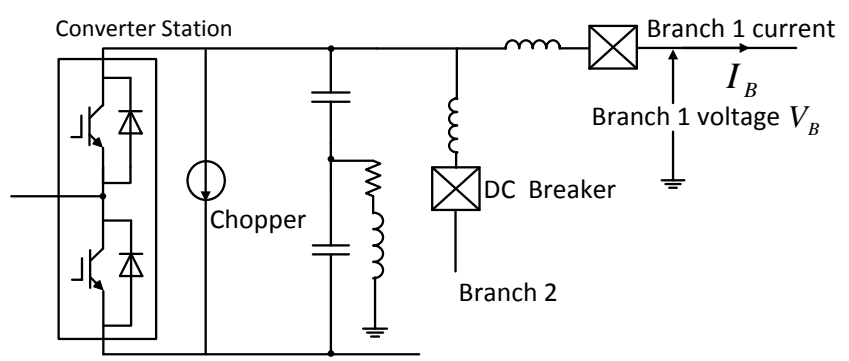

Figure 8: Location of each measured signal in Figure 7

\section{Performance of SCFCL in DC protection}

With respect to Figure 1, a pole-to-pole fault is introduced 20 $\mathrm{km}$ away from converter station A at 3 seconds. The DC system protection is achieved by using the DC circuit breaker, the SCFCL and the protection system shown in Figure 7.

Figure 9 shows the system fault current response comparison between the case when the SCFCLs are employed in the system and the case when there are no SCFCLs in the system. It can be seen from the first graph in Figure 9 that, with the help of the SCFCL, the peak fault current the DC circuit breaker needs to interrupt is reduced from $\sim 8 \mathrm{kA}$ to $\sim 7 \mathrm{kA}$, which means a breaker with lower current rating can be used in this case. The fourth graph in Figure 9 is the resistance response of the SCFCL. It can be seen from this graph that, as 
the fault current increases above the critical current $(1.8 \mathrm{kA}$ in this case), the resistance of the SCFCL $\left(\mathrm{R}_{\mathrm{SCFCL}}\right)$ rapidly develops. The initial oscillation in $\mathrm{R}_{\text {SCFCL }}$ is because as $\mathrm{R}_{\mathrm{SCFCL}}$ increases, at one point $\mathrm{R}_{\mathrm{SCFCL}}$ will be approximately the same value as $R_{\text {shunt }}$, after which more fault current will be diverted to flow through $\mathrm{R}_{\text {shunt }}$, as $\mathrm{R}_{\mathrm{SCFCL}}$ and $\mathrm{R}_{\text {shunt }}$ are connected in parallel, as shown in Figure 10.

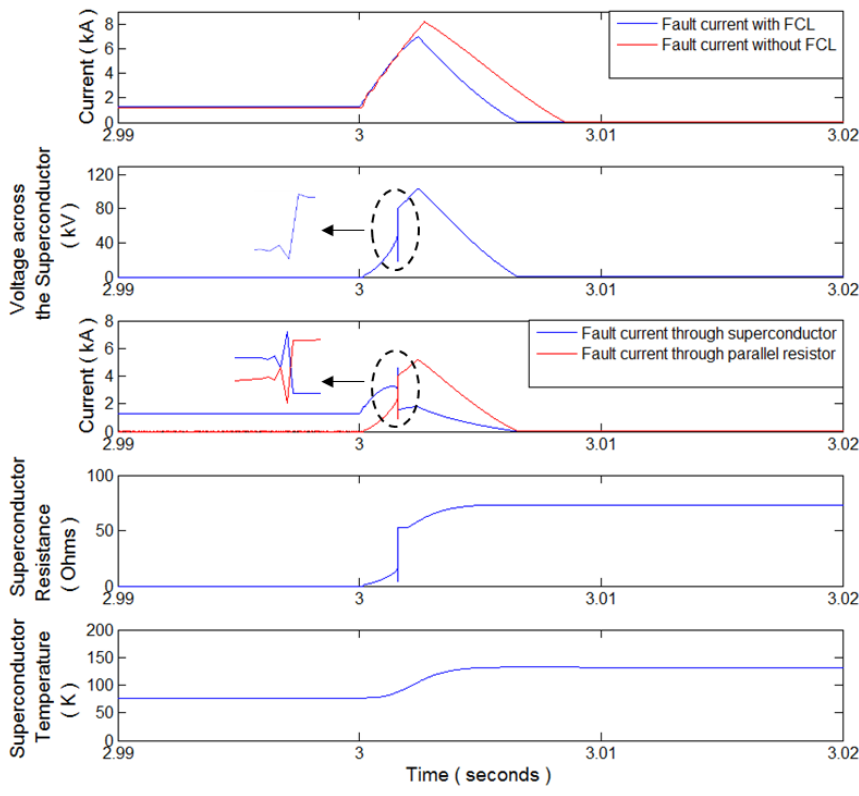

Figure 9: Simulation results of the fault current response with and without SCFCL

Less current will flow through $\mathrm{R}_{\mathrm{SCFCL}}$ and based on SCFCL flux-flow state equations (see Equation (1)) $R_{S C F C L}$ will reduce slightly. As $\mathrm{R}_{\text {SCFCL }}$ becomes smaller than $\mathrm{R}_{\text {shunt }}$, more current will flow through $\mathrm{R}_{\mathrm{SCFCL}}$ to heat the SCFCL. In the meantime, the total fault current is still increasing, therefore, $\mathrm{R}_{\mathrm{SCFCL}}$ will increase again. When the temperature of the SCFCL $\left(\mathrm{T}_{\mathrm{SCFCL}}\right)$ increases above the critical temperature, which is $95 \mathrm{~K}$ in this case, the resistance of the SCFCL will be determined by $\mathrm{T}_{\text {SCFCL }}$, see Equation (2). As the superconductor is heated up by the fault current, $\mathrm{T}_{\mathrm{SCFCL}}$ is increasing, and then $\mathrm{R}_{\mathrm{SCFCL}}$ will increase. Later, when $\mathrm{R}_{\mathrm{SCFCL}}$ is significantly higher than $\mathrm{R}_{\text {parallel }}$, most of the fault current will flow through the shunting resistor. Therefore, $\mathrm{T}_{\mathrm{SCFCL}}$ becomes steady and $\mathrm{R}_{\mathrm{SCFCL}}$ will not increase further.

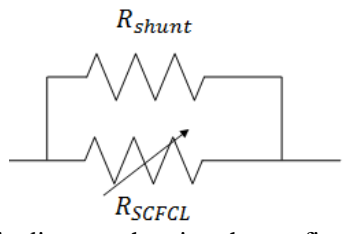

Figure 10: Schematic diagram showing the configuration of the SCFCL

It can also be seen that, in terms of the fault current limiting, initially, there is no significant difference between the case when the SCFCL is used and the case when the SCFCL is not used. This is due to the resistance of the SCFCL not being high enough to limit the fault current, the fault current is only limited when the SCFCL reaches the normal conducting stage, as the resistance of the SCFCL in this stage is significant. There is a trade-off between the value of $\mathrm{R}_{\text {shunt }}$ and the amount of fault current the SCFCL can limit. The higher the value of $R_{\text {shunt }}$, the lower the fault current can be limited to, but the voltage and temperature across the SCFCL will be higher.
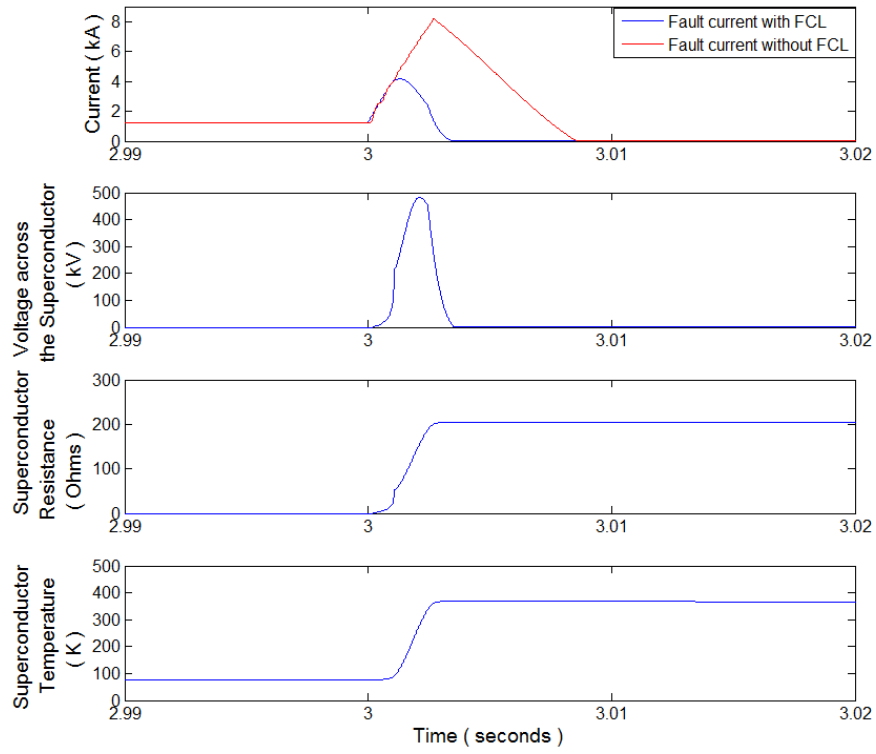

Figure 11: Simulation results of the fault current response without shunt resistor

If a shunt resistance is not placed in parallel with the SCFCL to limit fault current, Figure 11 shows the SCFCL response to the fault current under this circumstance. Compared with Figure 9, the fault current is further reduced to around $4.5 \mathrm{kA}$ in Figure 11. However, this is achieved at the expense of a much higher voltage across the SCFCL during the fault period, as $500 \mathrm{kV}$ in Figure 11 compared with $110 \mathrm{kV}$ in Figure 9. In addition, the temperature of the SCFCL rises to around $500 \mathrm{~K}$ in the case when there is no shunt resistor in parallel with the SCFCL, this may damage the SCFCL [37]. Therefore, the shunt resistor needs to be designed to give the compromise between SCFCL fault current quenching capability and voltage and temperature requirements of the SCFCL.

\section{Conclusions}

This paper conducts a study on the impact of the FCL exerts on the DC system protection. A detailed SCFCL model is used, together with the hybrid circuit breaker and the CWT algorithm to achieve the DC protection. The main findings are:

- The "Exponential" SCFCL modelling method cannot provide information about the temperature of the SCFCL during quenching stage.

- The resistive type SCFCL can be used in series with DC circuit breaker to help with DC fault protection. With the help of the SCFCL, the current rating of the DC circuit breaker can be reduced.

- A parallel resistance is needed for SCFCL to prevent it from experiencing overvoltage and overheat.

\section{Acknowledgements}

The authors gratefully acknowledge the contributions of Dr. Antony Beddard to the modelling of HVDC cable and MMC and Dr. Wenyuan Wang for his aid in the development of the 
converter control system, as well as the support of National Grid project TAO/22360 and EPSRC project FCL/B number: EP/L021552/1.

\section{References}

[1] ABBCompanyReport. Available: http://new.abb.com/systems/hvdc/references/borwin1

[2] SiemensCompanyReport. (2015). Available: http://www.siemens.com/press/en/feature/2013/energy/2013-08-xwin.php?content []=WP\&content []=PS\&content []=EM

[3] L. Xiaolin, Y. Zhichang, F. Jiao, W. Yizhen, L. Tao, and Z. Zhe, "Nanao multi-terminal VSC-HVDC project for integrating large-scale wind generation," in PESGM, IEEE, 2014, pp. 1-5.

[4] NRElectricCompanyReport. (2015). Available: http://www.nrec.com/en/news-content-253.html

[5] W. Wenyuan and M. Barnes, "Power Flow Algorithms for MultiTerminal VSC-HVDC With Droop Control," Power Systems, IEEE Transactions on, vol. 29, pp. 1721-1730, 2014.

[6] H. A. Anderson D, "Passive and active DC breakers in the three GorgesChangzhou HVDC project," Proceedings of the International Conference on Power Systems, pp. 391-395, 2001.

[7] A. B. Magnus Callavik, Jürgen Häfner, Björn Jacobson, "The Hybrid HVDC Breaker," ABB Grid SystemsNovember 2012.

[8] B.Chang, O.Cwikowski, M. Barnes, and R. Shuttleworth, "Multiterminal VSC-HVDC Pole-to-pole Fault Analysis and Fault Recovery Study," presented at the AC/DC, Birmingham, 2015.

[9] C. Meyer, M. Kowal, and R. W. De Doncker, "Circuit breaker concepts for future high-power DC-applications," in Industry Applications Conference. Fourtieth IAS Annual Meeting. Conference Record of the 2005, pp. 860-866 Vol. 2

[10]D. Jovcic and W. Bin, "Fast fault current interruption on high-power DC networks," in PESGM, IEEE, 2010, pp. 1-6.

[11]C. C. Davidson, R. S. Whitehouse, C. D. Barker, J. P. Dupraz, and W. Grieshaber, "A new ultra-fast HVDC Circuit breaker for meshed DC networks," in AC and DC Power Transmission, 11th IET International Conference on, 2015, pp. 1-7.

[12]T. Eriksson, M. Backman, and S. Halen, "A low loss mechanical HVDC breaker for HVDC Grid applications," presented at the CIGRE, Paris, 2014

[13]X. Pei, A. C. Smith, and M. Barnes, "superconducting fault current limiters for hvsc systems," presented at the Deep Sea Offshore Wind R\&D Conference, EERA DeepWind, Trondheim, Norway, 2015.

[14] M. A. Kumar, S. S. Babu, N. V. Srikanth, and Y. Chandrasekhar, "Performance of superconducting fault current limiter in offshore wind farm connected VSC based MTDC transmission system," in Power and Energy Conference at Illinois (PECI), IEEE, 2015, pp. 1-6.

[15]J.-G. Lee, U. A. Khan, S.-W. Lim, W.-j. Shin, I.-J. Seo, and B.-W. Lee, "Comparative study of superconducting fault current limiter both for LCC-HVDC and VSC-HVDC systems," Physica C: Superconductivity and its Applications.

[16]P. Manohar and W. Ahmed, "Superconducting fault current limiter to mitigate the effect of DC line fault in VSC-HVDC system," in EPSCICON, International Conference on, 2012, pp. 1-6.

[17] W. Wang, M. Barnes, and O. Marjanovic, "Droop control modelling and analysis of multi-terminal VSC-HVDC for offshore wind farms," in 10th IET International Conference on AC/DC, 2012, pp. 1-6.

[18] H. Chen, C. Wang, F. Zhang, and W. Pan, "Control Strategy Research of VSC Based Multiterminal HVDC System," in IEEE PES on Power Syst. Conf. and Expo. PSCE. , 2006, pp. 1986-1990.

[19]T. M. Haileselassie and K. Uhlen, "Impact of DC Line Voltage Drops on Power Flow of MTDC Using Droop Control," IEEE Transactions on Power System vol. 27, pp. 1441-1449, 2012.

[20]L. Jun, J. Tianjun, O. Gomis-Bellmunt, J. Ekanayake, and N. Jenkins, "Operation and Control of Multiterminal HVDC Transmission for Offshore Wind Farms," IEEE Transactions on Power Delivery, vol. 26, pp. 2596-2604, 2011

[21] J.Arrillage, High Voltage Direct Current Transmission vol. 6. London: Peter Peregrinus Ltd., 1983

[22] M. Mohammadi, M. Avendano-Mora, M. Barnes, and J. Y. Chan, "A study on Fault Ride-Through of VSC-connected offshore wind farms," in PES General Meeting, IEEE, 2013, pp. 1-5.
[23] U. N. Gnanarathna, A. M. Gole, and R. P. Jayasinghe, "Efficient Modeling of Modular Multilevel HVDC Converters (MMC) on Electromagnetic Transient Simulation Programs," IEEE Transactions on Power Delivery, vol. 26, pp. 316-324, 2011.

[24] J. Xu, C. Zhao, W. Liu, and C. Guo, "Accelerated Model of Modular Multilevel Converters in PSCAD/EMTDC," IEEE Transactions on Power Delivery, vol. 28, pp. 129-136, 2013.

[25] A. Beddard, M. Barnes, and R. Preece, "Comparison of Detailed Modeling Techniques for MMC Employed on VSC-HVDC Schemes," IEEE Transactions on Power Delivery, vol. PP, pp. 1-11, 2014

[26] W. Wang, A. Beddard, M. Barnes, and O. Marjanovic, "Analysis of Active Power Control for VSC-HVDC," IEEE Transactions on Power Delivery, vol. 29, pp. 1978-1988, 2014.

[27]Rao, C.N.R, and A. K. Raychaudhuri, "High Temperature Superconductors," in CRC Handbook of Chemistry and Physics, 77 ed: CRC Press, 1996.

[28]N. K. Singh and G. M. Burt, "Improved Model of Superconducting Fault Current Limiter for Power System Dynamic Studies," University of Strathclyde 2008.

[29] M. Itsuya, T. Doshita, T. Nakamura, T. Egi, and T. Hoshino, "Influences of superconducting fault current limiter (SFCL) on superconducting generator in one-machine double-line system," IEEE Transactions on Applied Superconductivity, vol. 13, pp. 2206-2209, 2003.

[30]L. Hee-Jin, S. Gum Tae, Y. Jae-Ik, and P. Jung-Wook, "Effect of a SFCL on Commutation Failure in a HVDC System," IEEE Transactions on Applied Superconductivity, vol. 23, pp. 5600104-5600104, 2013.

[31] W. Paul, M. Chen, M. Lakner, J. Rhyner, D. Braun, W. Lanz, and M. Kleimaier, "Superconducting fault current limiter: applications, technical and economical benefits, simulations and test results," CIGRE SC 13, Paris 2000.

[32] Y. Chen, S. Li, J. Sheng, Z. Jin, Z. Hong, and J. Gu, "Experimental and Numerical Study of Co-ordination of Resistive-Type Superconductor Fault Current Limiter and Relay Protection," Journal of Superconductivity and Novel Magnetism, vol. 26, pp. 3225-3230, 2013.

[33]K. De Kerf, K. Srivastava, M. Reza, D. Bekaert, S. Cole, D. Van Hertem, and R. Belmans, "Wavelet-based protection strategy for DC faults in multi-terminal VSC HVDC systems " IET, Generation, Transmission \& Distribution vol. 5, pp. 496-503, 2011

[34]D. Naidoo and N. M. Ijumba, "HVDC line protection for the proposed future HVDC systems," in International Conf. on Power Syst. Technology. PowerCon., 2004, pp. 1327-1332 Vol.2.

[35]S. Kucuksari and G. G. Karady, "Experimental Comparison of Conventional and Optical Current Transformers," IEEE Transactions on Power Delivery vol. 25, pp. 2455-2463, 2010.

[36] Trench, "HVDC Divider, Compensated voltage divider for HVDC transmission systems," TRENCH2012.

[37] A. Min Cheol, P. Dong Keun, Y. Seong Eun, K. Min Jae, K. Ho Min, K. Hyoungku, N. Kwanwoo, S. Bok-Yeol, P. Jung-Wook, and K. Tae Kuk, "A Study on the Design of the Stabilizer of Coated Conductor for Applying to SFCL," IEEE Transactions on Applied Superconductivity, vol. 17, pp. 1855-1858, 2007.

\section{Appendix}

\begin{tabular}{|c|l|c|}
\hline Variable & \multicolumn{1}{|c|}{ Definition } & Value \\
\hline$E_{C}$ & constant value & $1 \mu \mathrm{V} / \mathrm{cm}$ \\
\hline$E_{0}$ & Critical electric field across the SCFCL & $0.1 \mathrm{~V} / \mathrm{m}$ \\
\hline$J_{C}(77 \mathrm{~K})$ & Current density where $E=1 \mu \mathrm{V} / \mathrm{cm}$ & $1.5 \times 10^{7} \mathrm{~A} / \mathrm{m}^{2}$ \\
\hline$T_{c}$ & Critical temperature of the SCFCL & $95 \mathrm{~K}$ \\
\hline$T_{a}$ & Ambient temperature of the SCFCL & $77 \mathrm{~K}$ \\
\hline$\alpha$ & The flux-creep region constant & 6 \\
\hline$\beta$ & The flux-creep region constant & $1 \times 10^{-5} \Omega \mathrm{m}$ \\
\hline$\rho_{T_{C}}$ & Conducting resistivity of the SCFCL at $T_{C}$ & $1.5 \times 10^{3} \mathrm{~W} / \mathrm{Km}^{2}$ \\
\hline$k$ & $\begin{array}{l}\text { The coefficient of heat transfer to cooling } \\
\text { reservoir }\end{array}$ & $1.0 \times 10^{6} \mathrm{~J} / \mathrm{Km}^{3}$ \\
\hline$c_{v}$ & $\begin{array}{l}\text { The superconductor volumetric specific } \\
\text { heat }\end{array}$ & $200 \mathrm{~m}$ \\
\hline$l_{S C}$ & Length of the SCFCL & $3.48 \times 10^{-3} \mathrm{~m}$ \\
\hline $\mathrm{R}$ & Radius of the SCFCL & $20 \Omega$ \\
\hline$R_{\text {parallel }}$ & $\begin{array}{l}\text { Shunt resistance in parallel with the } \\
\text { superconductor }\end{array}$ & \\
\hline
\end{tabular}

Table 1: List of parameters used in SCFCL 